\title{
Long term GP opinions and involvement after a consultation-liaison intervention for mental health problems Nadia Younès*1,2,3, Christine Passerieux ${ }^{1}$, Marie-Christine Hardy-Bayle ${ }^{1,3}$, Bruno Falissard $2,4,5$ and Isabelle Gasquet ${ }^{2,4,6}$
}

Address: ${ }^{1}$ Academic Unit of Psychiatry, Versailles Hospital, Le Chesnay, France, ${ }^{2}$ INSERM U669, Hôpital Cochin, AP-HP, Paris, France, ${ }^{3}$ University of Versailles St Quentin en Yvelines (Paris Ile de France Ouest), Guyancourt, France, ${ }^{4}$ University Paris-Sud, Paris, France, ${ }^{5}$ University of Paris 5 , Paris, France and ${ }^{6}$ Direction of Medical Politicy, Paris, France

Email: Nadia Younès* - nadia.younes@noos.fr; Christine Passerieux - CPasserieux@ch-versailles.fr; Marie-Christine HardyBayle-MCHardyBayle@ch-versailles.fr; Bruno Falissard - falissard_b@wanadoo.fr; Isabelle Gasquet - isabelle.gasquet@sap.aphp.fr

* Corresponding author

Published: 2 July 2008

BMC Family Practice 2008, 9:4I doi:10.1|86/|47|-2296-9-4I
Received: 17 October 2007

Accepted: 2 July 2008

This article is available from: http://www.biomedcentral.com/I47I-2296/9/4I

(c) 2008 Younès et al; licensee BioMed Central Ltd.

This is an Open Access article distributed under the terms of the Creative Commons Attribution License (http://creativecommons.org/licenses/by/2.0), which permits unrestricted use, distribution, and reproduction in any medium, provided the original work is properly cited.

\begin{abstract}
Background: Shared Mental Health care between Psychiatry and Primary care has been developed to improve the care of common mental health problems but has not hitherto been adequately evaluated. The present study evaluated a consultation-liaison intervention with two objectives: to explore long-term GP opinions (relating to impact on their management and on patient medical outcome) and to determine the secondary referral rate, after a sufficient time lapse following the intervention to reflect a "real-world" primary care setting.

Methods: All the I39 collaborating GPs (response rate: $84.9 \%$ ) were invited two years after the intervention to complete a retrospective telephone survey for each patient (I8I patients; response rate: $69.6 \%)$.

Results: $91.2 \%$ of GPs evaluated effects as positive for primary care management (mainly as support) and $58.9 \%$ noted positive effects for patient medical outcome. Two years postintervention, management was shared care for $79.7 \%$ of patients (the GP as the psychiatric care provider) and care by a psychiatrist for $20.3 \%$ patients. Secondary referral occurred finally in $44.2 \%$ of cases.

Conclusion: The intervention supported GP partners in their management of patients with common mental health problems. Further studies are required on the appropriateness of the care provider.
\end{abstract}

\section{Background}

The care of common mental health problems, mainly provided in primary care, is known to be insufficient and to represent a major public health challenge. Collaborative care between Psychiatry and Primary care has been developed in several countries to address this problem $[1,2]$.
Evaluation of this kind of care is necessary. M Craven and $\mathrm{R}$ Bland reviewed the changing trends in collaborative care research: early studies were descriptive, and concerned with the impact on system outcomes. Then they focused on patient-level outcomes and quality improvement initiatives. Recently the ability of research-based 
programs to be translated into "real-world" settings has been examined [3]. Existing studies of shared mental health care considering a long-term outcome (more than a year) have focused on the patient [4]. They did not explore long-term GP opinions and long-term care delivery.

Two objectives were thus set out for the present study. First, to provide data on GP's opinions on the impact of the consultation-liaison system (after sufficient time had passed to enable a more "objectively" based view of the consultation system outcome), on their management of the patients they referred (rather than transferred) to the collaborative system, and on patient medical outcome. Second, to determine how frequently the family physician remained the primary care provider, alone or in conjunction with a mental health worker, after the shared mental health care intervention, with a sufficient time lapse following the intervention to reflect the real-world care delivery $[2,5,6]$.

\section{Methods}

A retrospective study was implemented in September 2004 , i.e three years after the start of the intervention.

The intervention involves a specialist consultation center intended for GPs in the geographic area ("South Yvelines" area to the west of Paris, 650000 inhabitants, 492 GPs) which is located in the biggest general hospital, less stigmatized than psychiatric hospitals [7]. Primary care physicians are invited to seek support for patients whom they consider pose a problem, without transferring the main responsibility to specialty care. The staffs is composed of Mental health professionals: two full-time equivalent psychiatric nurses, one full-time equivalent psychiatrist and one full-time equivalent psychologist. Each year since the start of the system 500 requests have been recorded. Patients referred to the consultation-liaison system by GPs are the main candidates, but direct requests from patients are also accepted if patients agree to a phone contact with their GP. A psychiatric nurse receives requests, comes into contact with the patient and systematically calls the GP to know his/her expectations about the intervention. Several responses are possible: direct orientation (specialized management for substance abuse or emergencies) after the phone contact without a specialized consultation $(22 \%)$ or, mainly, psychiatrist or psychologist consultations for advice or joint interventions (78\%). The objective of the intervention is to reach a decision on the way in which the patients should be catered for on the basis of the relationship with the GP, the expectations of both patient and GP, and the opinion of the consultant. No standard recommendations are used, except the required contacts with the GP subject to patient agreement (before the response, after consultation and a mail response). The intervention consisted for $41 \%$ of the patients in one consultation, for $31 \%$ in two or three consultations, and for $28 \%$ in more than three consultations. After the intervention, $30.0 \%$ of the patients were referred to a mental health facility and $70.0 \%$ returned to their GP. Every patient was informed before of the first consultation of the experimental care he will receive and gave written consent to researches on the intervention. The ethic committee of Paris Ile de France Ouest University gave approval for the study.

\section{Population}

The population was composed of the GPs ( $\mathrm{n}=139)$, who, as the main psychiatric care providers, received patients returned to them after the consultation-liaison intervention $(70.0 \%$ of the patients, since $30.0 \%$ were referred to the specialized care system). For these patients, GPs were invited to complete a retrospective telephone survey (260 patients expected), two years on average after the intervention $($ mean $=23.9$ months, $\mathrm{sd}=8.9, \min =6, \max =40)$. 3 attempts to contact GPs were fixed.

\section{Data collected}

The telephone questionnaire, requiring 10 minutes to complete, measured the way in which collaborative relationships developed between GPs and psychiatrists, GPs' opinions on the impact of the intervention, and continuing management after the intervention. Closed items were included for each type of data, completed with open items to explore referral reasons and GPs' opinions about the interventions.

\section{Data analysis}

Analyses were performed with SAS 8.2 software. Descriptive analyses were carried out on GPs' use of the consultations, collaborative relationships developed, GPs' satisfaction and patient care delivery. To exclude a memory bias for results, comparative analyses were carried out to ascertain that the time lapse between the consultation and the interview did not change results. As appropriate, the chi-square test was used for categorical variables and ANOVA tests for continuous variables. A 5\% p level of significance was chosen.

\section{Results}

118 GPs (response rate: $84.9 \%$ ) responded, giving information for 181 patients (response rate: 69.6\%). 3 GPs refused to answer. 10 GPs had moved from the area or had retired at the time of the survey. 8 GPs were not reached. Among the 181 patients, 167 (92.3\%) were still being seen by the GP at the time of the survey. 


\section{Shared mental health intervention (patient profiles and} management implemented within the intervention)

Patients were $77.5 \%$ female, mean age 39.7 years ( $\mathrm{sd}=$ 14.4). 60.6\% had a current professional activity. According to the main CIM-X diagnoses established by the psychiatrist at the time of the intervention, $60.4 \%$ of patients presented a mood disorder, $14.6 \%$ an anxiety disorder, $18.1 \%$ a personality disorder and $6.9 \%$ another type of disorder. Comorbidity was noted for $28.7 \%$.

GPs referred $64.7 \%$ of the patient population concerned by the intervention (30.9\% came of their own accord or were referred by their family and for $4.3 \%$, data were not available). Among patients referred to the consultationliaison system by GPs, $84.8 \%$ were referred because of diagnosis or therapeutic difficulties, $9.3 \%$ on patient or family demand and 5.9\% for a specialized follow-up. GPs reported that in some cases it was a long time before the patient agreed to consult, and that knowing that a consultation was offered without actual transfer to the specialist system convinced certain reluctant patients.

Management implemented within the intervention was mainly collaborative, entailing dealings between GP and psychiatrists for $73.9 \%$ of patients, or for $18.5 \%$ no contact, but where this was understood by the GP (for instance when patients for personal reasons did not wish for it). GPs reported, and deplored, a lack of these collaborative relationships for $7.6 \%$ of patients. Collaborative dealings were more frequent for patients referred to the system by GPs than when patients themselves resorted to this consultation $(\mathrm{p}<.001)$.

\section{Long term opinions on the shared mental health care intervention}

Regarding GPs' long-term opinions on the intervention, most GPs were satisfied with the intervention (table 1).

The intervention provided technical management assistance for a third of patients, via changes in GPs' management (change in medication, psychotherapy orientation). According to the GPs, the main impact of the intervention was to provide support assistance for half of the patients, backing up GP management in case of patient reluctance towards treatment for example, or in case of doubt on the appropriate care on the part of the GP. The usefulness of a third party in the relationship was highlighted for $10.4 \%$ patients. GPs mentioned negative consequences for $8.8 \%$ patients, such as a feeling of "dispossession", disagreement between GP and mental health specialist, or confusing numbers of care-givers for the patient and for the GP.

Regarding patient medical outcome, GPs reported a positive outcome for more than half of the patients and no change for a third.

\section{Long term care delivery: secondary referral rate}

After the intervention, GPs remained the care providers for the psychiatric management for eight referred patients out of ten (table 1). The consultation-liaison was re-

Table I: Long term GP opinions and care delivery after the consultation-liaison (23.8 months on average, N = I I8 GPs and I8 I patients)

Long term GP opinions on the impact of the intervention (\%)

GPs' opinions on the impact for primary care management (several answers possible)

Technical management assistance

Support assistance

Third party role

Negative impact
31.2

51.2

10.4

8.8

GPs' opinions on patient medical outcome

Positive outcome

No change

Negative outcome
66.8

31.7

1.5

Long-term care delivery: main care provider (\%)

GP

alone

with psychologist

with another professional

Psychiatrist (public or private practice)

GPs' opinions on patient medical outcome 
applied for $4.9 \%$ but knowing that it remained a possibility was helpful for most GPs. Classic psychiatric referral occurred for $20.3 \%$ of the patients.

\section{Discussion}

This paper aimed to evaluate the impact of a specific collaboration intervention in real-world practice, focusing on its main users, GPs. Its strength is that it provides data from GPs on the impact of the consultation-liaison system after sufficient time lapse, incorporating, for most patients, information about how practicable the specialized advice was and whether the GP and the patient finally benefited from it or not (long-term opinions were based, for $72 \%$ of patients, on recent consultations, since only $18 \%$ were not seen during the period following the intervention). A design of this type is more powerful than a study asking these questions immediately after the intervention. The patient population was derived from a primary care population, and included anxiety disorders and personality disorders that are underrepresented in the literature [4,8-12].

\section{Limitations}

Caution is required in the interpretation of a descriptive study based on GPs' responses collected through personal interviews, and reflecting individuals' subjective experiences, even though a high response rate was registered. The reliability and validity of a telephone questionnaire might also be questionable.

An important limitation requires discussion, and that is the particular nature of a retrospective study, the relevance of which could be more debatable because time lapses differed according to patients. This implies a possible memory bias, since recall could differ according to the time lapse between the consultation and the interview of the GP (with a median time lapse of 23.9 months). However it was possible to ascertain that this effect not significant for this survey, by implementing a t-test to determine whether the time lapse parameter differed in its relationship with the main indicators (long-term positive opinions or not, long-term secondary referral or not) and with the main confounders (patients still seen by the GP or lost, patients referred to the system by the GP or not, collaborating relationships established or not). Results were non significant.

Finally, and more seriously, the assessment focused only GPs' opinions and was not completed by independent assessments, blind to the intervention, nor by objective measurements (these may not been linked, as shown for GPs' knowledge and management of mental disorders) $[5,13,14]$.

\section{Long term opinions on the shared mental health care intervention}

GPs made use of the intervention, referring 65\% of patients to the system, which is much more than the GP referral percentage found before the Mental Health Organizational Intervention for traditional psychiatrist consultation (25.1\%) [15].

GPs' satisfaction with collaborative programs is known to be high $[2,16,17]$. The study explored the helpfulness of shared mental health care according to GPs, who had highlighted a need for support in a prior survey [15]. It is noteworthy that GPs reported technical management assistance for only a third of the patients and evaluated the impact of the intervention mainly as support assistance without fundamental changes in GPs' management. It is as if an intervention of this nature provides more a form of "emotional" support for complicated patients that GPs are managing in primary care, than technical management assistance.

Results, based on opinions of the GPs, have thus confirmed the benefit for primary care management and for patient medical outcome that has also been reported in the literature. The study adds to the literature by reporting positive opinions on the system and on patient outcome, even when some time had elapsed since GPs had actually referred the patients, suggesting that this mode of care is able to create a more collegiate and collaborative relationship between primary care providers and the "formal" mental health care system [6,17-20].

\section{Long term care delivery after the shared mental health care intervention}

The main result of the study confirms the hypothesis: the GP remained the primary care provider at a distance of two years from the start of the consultation-liaison intervention. The main service delivery pattern was thus primary care, in conjunction with the support of the consultation-liaison staff, who could be required to reintervene but who actually intervened a second time or more for less than $5 \%$ of patients. By adding the proportion of patients referred secondarily just after the consultation $(30.0 \%)$ and those referred at a later date $(20.3 \%$, i.e $14.2 \%$ of the initial group of $70 \%$ of patients), it can be considered that secondary referral occurred in $44.2 \%$ of cases. This proportion is coherent with the literature (18$44 \%$ ). But in our survey, for the first time, a two-year average time lapse was ensured four years on from the start of the intervention, and this time lapse is sufficient to conclude that GPs' de-motivation shown in some research into collaborative mental health care has not been confirmed here $[2,17,20,21]$. Further studies are still required regarding the appropriateness of the care provider. 


\section{Conclusion}

The intervention supported GP partners in their management of patients with common mental health problems. Further studies are required on the appropriateness of the care provider.

\section{Abbreviations}

GP: General Practitioner; GPs: General Practitioners; CIM$\mathrm{X}$ : International classification of diseases.

\section{Competing interests}

The authors declare that they have no competing interests.

\section{Authors' contributions}

NY conceived the study, participated in its design and in the acquisition of data, performed the statistical analysis and drafted the manuscript. CP drafted the manuscript. $\mathrm{M}-\mathrm{CH}-\mathrm{B}$ conceived the study and participated in its design. BF provided methodological and statistical expertise. IG participated in the interpretation of the data. All authors read and approved the final manuscript.

\section{Acknowledgements}

The survey was made possible through MIRE INSERM funding

\section{References}

I. Gilbody S, Whitty P, Grimshaw J, Thomas R: Educational and organizational interventions to improve the management of depression in primary care: a systematic review. Jama 2003, 289:3|45-3|5|.

2. Craven MA, Bland R: Shared mental health care: a bibliography and overview. Can J Psychiatry 2002, 47:iS-viiiS, IS-I03S.

3. Craven MA, Bland R: Better practices in collaborative mental health care: an analysis of the evidence base. Can J Psychiatry 2006, 5 I (6 Suppl I):7S-72S.

4. Arthur A], Jagger C, Lindesay J, Matthews RJ: Evaluating a mental health assessment for older people with depressive symptoms in general practice: a randomised controlled trial. $\mathrm{Br}$ J Gen Pract 2002, 52(476):202-207.

5. Warner RW, Gater R, Jackson MG, Goldberg DP: Effects of a community mental health service on the practice and attitudes of general practitioners. Br I Gen Pract 1993, 43(377):507-5 I I.

6. Turner T, de Sorkin A: Sharing psychiatric care with primary care physicians: the Toronto Doctors Hospital experience (1991-1995). Can J Psychiatry 1997, 42(9):950-954.

7. Younes N, Hardy-Bayle MC, Falissard B, Kovess V, Chaillet MP, Gasquet I: Differing mental health practice among general practitioners, private psychiatrists and public psychiatrists. $B M C$ Public Health 2005, 5:104.

8. Katon W, Russo J, Von Korff M, Lin E, Simon G, Bush T, Ludman E, Walker E: Long-term effects of a collaborative care intervention in persistently depressed primary care patients. J Gen Intern Med 2002, 17:741-748.

9. Wells KB, Sherbourne C, Schoenbaum M, Duan N, Meredith L, Unutzer J, Miranda J, Carney MF, Rubenstein LV: Impact of disseminating quality improvement programs for depression in managed primary care: a randomized controlled trial. Jama 2000, 283:2 12-220.

10. Rubenstein LV, Jackson-Triche M, Unutzer J, Miranda J, Minnium K, Pearson ML, Wells KB: Evidence-based care for depression in managed primary care practices. Health Aff (Millwood) 1999, I 8:89-105.

II. Coleman EA, Grothaus LC, Sandhu N, Wagner EH: Chronic care clinics: a randomized controlled trial of a new model of primary care for frail older adults. J Am Geriatr Soc 1999, 47(7):775-783.
12. Blanchard MR, Waterreus $A$, Mann $A H$ : Can a brief intervention have a longer-term benefit? The case of the research nurse and depressed older people in the community. Int J Geriatr Psychiatry 1999, I4:733-738.

13. Carr VJ, Donovan P: Psychiatry in general practice. A pilot scheme using the liaison-attachment model. Med ] Aust 1992 I 56(6):379-382.

14. Katon W, Robinson P, Von Korff M, Lin E, Bush T, Ludman E, Simon G, Walker E: A multifaceted intervention to improve treatment of depression in primary care. Arch Gen Psychiatry 1996, 53(1 0):924-932.

15. Younes N, Gasquet I, Gaudebout P, Chaillet MP, Kovess V, Falissard B, Hardy Bayle MC: General Practitioners' opinions on their practice in mental health and their collaboration with mental health professionals. BMC Fam Pract 2005, 6:18.

16. Strathdee G: Psychiatrists in primary care: the general practitioner viewpoint. Fam Pract 1988, 5: I I I-II 5.

17. Kates N, Craven MA, Crustolo AM, Nikolaou L, Allen C, Farrar S: Sharing care: the psychiatrist in the family physician's office. Can J Psychiatry 1997, 42:960-965.

18. Strathdee G, Brown RM, Doig RJ: Psychiatric clinics in primary care. The effect on general practitioner referral patterns. Soc Psychiatry Psychiatr Epidemiol 1990, 25(2):95-100.

19. Pullen IM, Yellowlees AJ: Scottish psychiatrists in primary health-care settings. A silent majority. $B r$ J Psychiatry 1988, I 53:663-666.

20. Biderman A, Yeheskel A, Tandeter H, Umansky R: Advantages of the psychiatric liaison-attachment scheme in a family medicine clinic. Isr J Psychiatry Relat Sci 1999, 36(2): I I 5-I2I.

21. Carr VJ, Faehrmann C, Lewin TJ, Walton JM, Reid AA: Determining the effect that consultation-liaison psychiatry in primary care has on family physicians' psychiatric knowledge and practice. Psychosomatics 1997, 38(3):217-229.

\section{Pre-publication history}

The pre-publication history for this paper can be accessed here:

http://www.biomedcentral.com/1471-2296/9/41/prepub
Publish with Bio Med Central and every scientist can read your work free of charge

"BioMed Central will be the most significant development for disseminating the results of biomedical research in our lifetime. "

Sir Paul Nurse, Cancer Research UK

Your research papers will be:

- available free of charge to the entire biomedical community

- peer reviewed and published immediately upon acceptance

- cited in PubMed and archived on PubMed Central

- yours - you keep the copyright 